\title{
Wine as an Alternative Asset Class*
}

\author{
Philippe Masset ${ }^{\mathrm{a}}$ and Caroline Henderson ${ }^{\mathrm{b}}$
}

\begin{abstract}
Using a dataset that spans the period 1996 to 2007 and contains transaction prices for all reported auctions at the Chicago Wine Company, we analyze how the prices of high-end wines have evolved during this time period. The best wines according to characteristics like vintage, rating and ranking earn higher returns and tend to have a lower variance than poorer wines. Nevertheless, the different categories of wines seem to follow a rather similar trend over the long run. Wine returns are only slightly correlated with other assets and can consequently be used to reduce the risk of an equity portfolio. Wine looks even more attractive when the investor also has concerns about the skewness of his portfolio. However, the part to be invested in wine is reduced once the kurtosis is included into the analysis. Finally, it seems advisable to diversify across different wine categories as their short-run movements are partially independent of each other. First growths and wines rated as extraordinary by Robert Parker deliver the best tradeoff in terms of portfolio expected returns, variance, skewness and kurtosis for most investor preference settings under consideration. (JEL Classification: C60, G1 I, Q11)
\end{abstract}

\section{Introduction}

During the last few years, wine has been increasingly considered as an alternative investment vehicle. Wine prices have experienced strong inflation (at least until summer 2008). This is particularly true for those wines produced by the most prestigious estates in famous areas like Bordeaux or Burgundy. The demand for these wines has increased because of the massive arrival of new customers from Russia and Asia and also because of bullish financial markets, which have had an emulation effect on other markets (e.g. collectibles). Moreover, the rarefaction of attractive investment opportunities on financial markets has probably led some investors to reinvest part of their gains on the wine market (see Burton and Jacobsen, 1999). This interest for investing in wines is not restricted to professional investors. A number of articles have been published in popular newspapers and magazines. There are also several investment funds aiming at tracking the performance of the wine

* We are grateful to an anonymous referee and the editor, Karl Storchmann, for their valuable comments and suggestions on earlier versions of this paper.

a Ecole hôtelière de Lausanne, Case postale 37, 1000 Lausanne 25, Switzerland, email: philippe.masset@ehl.ch

b University of Lausanne, Department of Art History, email: caroline.henderson@unil.ch 
market. ${ }^{1}$ Euronext launched a wine futures market, the WineFex in 2001; however, it failed to attract sufficient attention from investors and thus disappeared by the end of 2002.

Despite this growing interest in wine as an asset class, finance academics have devoted only limited attention to this realm of research since the pioneering works of Krasker (1979) and Jaeger (1981). ${ }^{2}$ Since the late 60's, wine has indeed been presented as a possibly attractive alternative investment (see, e.g., the references in Krasker, 1979). The first attempts to assess formaly the validity of this popular belief lead however to mixed results. Krasker (1979) arrives at the conclusion that wine returns are close to the returns on riskless assets. Jaeger (1981) argues that the poor returns reported in Krasker's study could be due to the specific time period considered (1973-1977, 137 observations), which essentially coincides with the oil crisis. Using a sample covering years 1969 to 1977 (199 observations), Jaeger demonstrates that investing in wines can be lucrative.

According to Burton and Jacobsen (1999), collectibles (including wines) are characterized by a higher variance than equities and their price evolution has a typical boom-burst aspect. $^{3}$ The latter is confirmed by Fogarty (2006b) who notes that the returns on wine are cyclical. Furthermore, the correlation among various collectible categories seems to increase in falling markets (Burton and Jacobsen, 1999). Burton and Jacobsen (2001) argue that the returns on wine should be higher than for other collectibles (as its consumption implies destruction) but lower than for stocks (as it provides an intrinsic utility to its beneficiary). These theoretical insights are indeed confirmed by their empirical analysis: wines typically achieve lower Sharpe ratio than stocks. Nevertheless, Burton and Jacobsen (2001) also show that the performance of some specific wine portfolios might be more attractive; in particular, the returns of a portfolio consisting only of wines from the 1982 vintage compare favourably with that of the Dow Jones. More recently, Fogarty (2006b) shows that the returns on premium Australian wines have been almost as large as the returns on Australian equities over the period 1989-2000, while their volatility has been significantly lower than that of Australian equities. Fogarty (2006b) also demonstrates that more expensive wines achieve larger returns and have a lower volatility than less expensive wines.

All the previously mentioned studies have focused on returns and risk solely and have basically compared wines and equities on the basis of these features alone. A problem with such an approach is that it completely disregards the potential benefits of wine in terms of diversification. For a well-diversified investor, it is not sufficient to look at the return and

\footnotetext{
' Some funds invest in wine companies (see, e.g., The Orange Wine Fund), while others invest directly in wines (see, e.g., The Vintage Wine Fund or The Wine Investment Fund).

${ }^{2}$ Many papers have addressed the question of how wine is priced; most of them are based on hedonic models; see Ashenfelter et al. (1995), De Vittorio and Ginsburgh (1996), Combris, Lecocq and Visser (1997), Combris, Lecocq and Visser (2000), Jones and Storchmann (2001), Oczkowski (2001), Cardebat and Figuet (2004), Fogarty (2006a) and Lecocq and Visser (2006), Benfratello, Piacenza and Sacchetto (2009) and Ashenfelter (2010). In particular Fogarty (2006a) focuses on Australian wines and provides a thorough literature review.

${ }^{3}$ For instance, De Vittorio and Ginsburgh (1996) report that prices have increased by $75 \%$ between 1981 and 1990 and have then decreased by $15 \%$ (up to 1992).
} 
the risk of an investment to assess its profitability. What is relevant is the ability of such an investment to deliver a return in excess of some benchmark rate of return. To the best of our knowledge, only two papers have tried to assess this issue. Fogarty (2007) derives the optimal frontier for two cases. In the first case, only stocks and bonds are considered, while in the second case the investment universe also includes wines. The results show that the efficient frontier is shifted to the left in case two. Thus it is possible to construct a portfolio with a better risk-return tradeoff when wines are also taken into account. Sanning, Shaffer and Sharratt (2008) use both the Capital Asset Pricing Model and the Fama-French three factors model to assess the risk-return profile of wines as compared to equities. Their results indicate that wines have a low covariance with both the market and the Fama-French risk factors and hence they might be used to improve the diversification of an equity portfolio. They further point out that an investment in wines is rewarded by an excess return that cannot be explained by the model (i.e. the alpha is positive and significant).

The goals of this paper are the following: (1) we characterize the evolution of high-end wine prices during the last decade, (2) we study long-run, short-run and causality relationships between various wine categories (from first growths to fifth growths) in order to gain a better understanding of the dynamics affecting the wine market, and, (3) we address the question of diversification and portfolio allocation in a realistic setting, which includes equities, wines and art works. To achieve this aim, we make use of a large dataset that spans the period 1996 to 2007 and contains the transaction prices of all reported auctions at the Chicago Wine Company. We focus on Bordeaux wines as they represent more than $90 \%$ of the worldwide market for high-end wines. We devote much attention to the preparation of the data and carefully control for errors in the dataset. We end up with 77,014 transactions for 92 Bordeaux estates and 29 vintages.

While some authors have already studied the dynamics of wine prices and their interactions with other financial assets, our paper differs in several respects from earlier works. First of all, the length of our dataset and the frequency of observations permit to complement prior evidence on the features of wine investing. The recent studies of both Fogarty (2007) and Sanning, Shaffer and Sharratt (2008) use samples that end respectively in 2000 and 2003. Our dataset also covers the period from 2004 to 2007, which is often considered as the golden age for wine investing. But stock markets have boomed at the same time and thus it is unclear whether investing in the wine market has been sufficiently rewarding as compared to an investment in equities. In fact, our results indicate that not only the individual performance of wine has been interesting in terms of risk-return trade-off but also that its correlation with equities has remained sufficiently low to maintain its attractive feature as a diversification asset. Because we use monthly data (only Sanning, Shaffer and Sharratt (2008) use a similar frequency) we are also able to analyze precisely the statistical features of wine returns. In particular, the skewness is consistently positive, which is contrary to what is observed on stock markets. The kurtosis always exceeds the threshold value of three and is in general larger than for stocks. These two observations could have important implications for investors as they typically want to maximize the skewness of their portfolio while minimizing its kurtosis. 
Our first contribution is that we characterize precisely the returns for different wine categories and verify if it is more profitable to invest in particular wines rather than in a diversified wine portfolio. Several studies have demonstrated that characteristics like vintage, rating and ranking have an impact on pricing. We go beyond this static perspective and show that those characteristics are also important determinants of the returns over time of such wines. Burton and Jacobsen (1999) discuss the fact that returns on specific sub-market portfolios (e.g., portfolios based on outstanding vintages or highly reputable estates) tend to outperform the returns on the overall wine market. Nevertheless, the evidence on this point is mixed. The results in Jaeger (1981) indicate that returns on lesser estates might be larger but also more volatile than those of the best estates. Burton and Jacobsen (2001) find that a general index indeed achieves larger returns than the best estates. We find that wines that are good at one or several of these characteristics earn larger returns and tend to have either a lower or a similar variance than less good wines. A positive premium seems to be attached to these attributes even if an exposition to them does not imply more risk; this looks somewhat counterintuitive and may indeed suggest the presence of inefficiencies on the wine market.

Our second contribution is to study in details long-run, short-run and causal relationships among three categories of Bordeaux wines: first growths, second growths and third to fifth growths. A potential explanation for the aforementioned observation that first and second growths earn larger returns than wines from lesser estates might be that the market is segmented. If, for instance, investors perceive the most prestigious wines as investment grade and merely consider their followers as consumption goods, then investors will most probably not invest in lower ranking wines. As a consequence, those wines will not enter investors' portfolios and, thus, their Sharpe ratio becomes irrelevant. We test this argument and show that it is actually not valid: the three wine categories seem to follow a common long term trend as the hypothesis that a single cointegration relationship links their evolution cannot be rejected. We also document strong correlations between the returns on the three wine categories. In particular, the correlation between first and second growth is large (about 50\%) and remains very stable all over the sample period. The correlations between third to fifth growths and first or second growths is less stable but nevertheless important (between $20 \%$ and $70 \%$ ). Finally, we do not find evidence in favor of a causal relationship running from one category to another. This indicates that price evolution is almost synchronous among all categories of wines.

Our third, and probably main, contribution is that we address the question of diversification and portfolio allocation in a realistic setting that accounts for covariance between equities and wines and also for coskewness and cokurtosis. As written above, the evidence concerning the profitability of an investment in wine as compared to an investment in equity is mixed. Yet even if wine does not deliver an attractive risk-return profile per se, it might still improve an equity portfolio through diversification. Several authors argue that focusing on the first two moments of the joint distribution (as in the mean-variance framework of Markowitz (1952) disregards important aspects of the investor preferences and utility function (see Jondeau and Rockinger, 2006). Furthermore, wines and equities seem to have different marginal distributions and their joint distribution might also diverge from the normal. We therefore employ a polynomial goal programming (PGP) model (e.g., Lay et al., 2006; Davies et al., 2009) to investigate how investor preferences over the first four 
moments of the returns distribution affect the portfolio allocation and the distribution of its returns. In line with Fogarty (2007), we show that wines are only slightly correlated with other assets and as such they can be used to reduce the risk of an equity portfolio. The allocation in the optimal portfolio contains a large part of the most reputable wines because of their high expected returns. This result is robust to various specifications (e.g., including other assets like art works into the analysis) and still holds after having taken into account the various costs inherent to the trading of wines. Wines look even more attractive when the investor also has concerns about the skewness of his portfolio. However, extending the framework to include the kurtosis reduces the part to be invested in wines. Finally, it seems advisable to diversify across the range of rating categories as their moves in the short-run are somewhat independent of each other. First growths and wines rated 100 by Robert Parker deliver the best tradeoff in terms of portfolio expected returns, variance, skewness and kurtosis for most investor preference settings.

This paper is structured as follows. Section 2 is devoted to the preparation of the data and the calculation of the wine indices. Section 3 presents and discusses the evolution of each index. In section 4, we analyze both the long- and short-run relationships between various categories of wines. In section 5, we study the optimal allocation between equities and wines, first in a standard mean-variance setting and then in a framework including skewness and kurtosis. Section 6 discusses the impact of the financial crisis on wine prices. Section 7 concludes.

\section{Data and Index Construction}

\section{A. Data}

Our data come from the Chicago Wine Company and cover all auctions that took place between January, 1996 and February, 2007. There is typically one auction per calendar month. However, there are also few months in which no auction took place. In total, our sample consists of 126 months with auctions. We concentrate on the prices of red Bordeaux because they are the most speculative and actively traded wines all over the world. For instance, they account for more than 93\% of the Liv-ex 100-Fine Wine Index (as of January 2008). ${ }^{4}$ Only transactions involving $0.75 \mathrm{~L}$ bottles are taken into account. Other formats are traded less frequently and their prices can be subject to erratic changes. There were some mistakes in the original database (e.g., typos or inaccurate entries). These errors were identified and the original entry either corrected or removed depending on whether we could infer the true information from the original dataset or not.

Only few Châteaux can be considered as investment-grade. Indeed many Châteaux remain in the shadow of the biggest names, on which most of the trading activity concentrates. The notoriety of those Châteaux is the result of both their historical situation ${ }^{5}$ and the current

\footnotetext{
${ }^{4}$ Source: Liv-ex 100 Component List (www.liv-ex.com).

${ }^{5}$ For instance, the 1855 classification is still in use. With the exception of Château Mouton Rothschild, which was upgraded in 1974, the short list of first growths has not changed since 1855 !
} 
quality level of the wines they produce. ${ }^{6,7}$ We therefore focus on a subset of 92 estates that are actively traded. We classify them into five ranking categories, which are the following: first growths (11 estates), second growths ${ }^{8}(12)$, third growths (13), fourth growths (13) and fifth growths (27). We also consider two additional categories: second wines (6) and garage wines (10). Wines from the last two categories are, however, much less frequently traded than the others. Châteaux names are listed in the appendix (their official ranking and the appellation to which they belong are also reported). Our five-tier classification does not match the official one for two reasons. First, in some appellations like Pomerol, no official classification exists. Second, some Châteaux do not deserve their original classification anymore and have not been included; similarly others perform much better than their original classification would indicate. Our classification is mainly based on the trading volume, the en primeur ${ }^{9}$ pricing and the reputation of each Château over the 11 year sample.

The wine production in the region of Bordeaux does not achieve the same quality each year. This is due to the typical oceanic climate which is affected by the North Atlantic current. The weather can be rather erratic and each year displays its own features. Hence, every vintage is unique. In recent years, 1982, 1990, 2000 and 2005 turned out to be exceptional. On the other hand, 1984, 1987, 1991, 1992 and 1993 were (almost) of no interest. Amateurs focus on above average vintages and so is the trading activity. We consider all post-1977 vintages (excluding 1980, 1984, 1987 and 1991-93) up to 2003, and some famous vintages like 1945, 1947, 1955, 1959, 1961, 1966, 1970 and 1975.

We eventually end up with a dataset containing 77,014 transactions for 92 Châteaux and 29 vintages. If a wine has been traded more than once at a particular auction, we set its monthly closing price equal to the average price achieved at this auction. If no trade has been recorded in a given month for a given wine, we set its price to the previous month closing price.

\section{B. Index Construction}

We compute a variety of indices using a method, which is very similar to the one employed for stock market indices. That is, the estimation of "our" wine indices is based on weighted average of the observed wine prices. ${ }^{10}$ Two alternative routes can be followed to construct

\footnotetext{
${ }^{6}$ The latter can be assessed through the ratings they got from, e.g., the Wine Advocate (Robert Parker), Wine Spectator, Jancis Robinson and Quarin.

7 The Saint-Emilion classification is different from the 1855 classification as it is updated every 10 years. It is based on the current level of quality achieved by each estate and the prices at which their recent vintages trade.

${ }^{8}$ Amateurs usually refer to these wines as the super seconds. This denomination comes from the fact that many estates that have not been originally classified as first growth (or even as second growth) are now considered by wine critics as achieving a quality level very close to that of first growths.

${ }^{9}$ Bordeaux estates market most of their wines as en primeur in the spring following the harvest. At that moment, the wines are still in cask. Thus, customers do not directly get the wines but have to wait until they are bottled. Buying wines en primeur can be considered as a way to secure wines that might be in short supply; this is also a hedge against rising prices. From a financial point of view, this type of transaction very much resembles a future contract. ${ }^{10}$ See also the discussion and comparison of these methods in Burton and Jacobsen (1999).
} 
a wine index: the first is based on a hedonic pricing regression, while the second uses a repeat sales regression. Hereafter we briefly present each of these three methods and justify our choice in favor of the weighted average approach.

\section{Brief presentation of the hedonic, repeat sales regression and weighted average methods}

The literature on price indices (for consumption goods, including wines) relies extensively on the hedonic pricing method. ${ }^{11}$ The idea is to split the price into two components; one corresponds to the value attached to some intrinsic features of the good (its quality, rarity, etc.), while the other part measures the price appreciation over time. It is thus possible to account explicitly for the heterogeneity among the different wines. Hedonic regressions typically involve huge matrices of regressors (with many dummy variables), which leads to multicollinearity problems ${ }^{12}$ and renders the index coefficients imprecise and erratic. This is the major drawback of this approach and this why we avoid using it.

The repeat sales regression (RSR) approach is extensively used for estimating housing indices. ${ }^{13}$ The underlying idea is to consider only those (similar) goods that have been traded at least twice during the period under consideration. One can compute the return between two transaction prices and then attribute this total return to the different subperiods. It has the advantage over the hedonic method that it compares the price evolution of similar goods. It is, thus, not necessary to calibrate a model to account for the differing features of the good under consideration (i.e. no dummy variable is involved). Nevertheless, it also has some drawbacks. First, the index is likely to be updated ex-post. This is because the index level for a given month is definitely fixed only when all goods that have been traded up to this month have been traded again. As a consequence, the true level of the index at time $t$ will not be known before $t+k$ $(k \geq 0)$. Another problem with this method is the potential impact of outliers on the estimated index values. The point is that (i) the number of wines sold at each auction can vary considerably, (ii) a few wines attract most of the interest from investors, while other are seldom traded. So, if the number of wines sold at a particular auction date is small (as compared to other auction dates) and if the prices of these wines diverge significantly from their fair value (i.e. if they are very different from the prices recorded during surrounding auctions), the evolution of the index will reflect this change even if it is only temporary.

\footnotetext{
${ }^{11}$ See, e.g., Jones and Storchmann (2001), Lecocq and Visser (2006), Combris, Lecocq and Visser (1997), Combris, Lecocq and Visser (2000), Cardebat and Figuet (2004), Oczkowski (2001), Benfratello, Piacenza and Sacchetto (2009) and De Vittorio and Ginsburgh (1996). Fogarty (2006a) provides an exhaustive and up-to-date literature review on hedonic pricing.

${ }^{12}$ For instance, De Vittorio and Ginsburgh (1996) make use of the hedonic approach and find that a vintage like 1954, which is considered a "worse than average" vintage, outperforms every other vintage (including the great 1961). They also have to exclude vintage 1982 from the analysis because of multicollinearity problems.

${ }^{13}$ In the wine economics literature, it has recently been used by Burton and Jacobsen (2001).
} 
As already written, the method we use is a weighted average of the index components (wines) prices. This approach is not only simple to implement but also very flexible and it does not suffer from the drawbacks of the RSR and hedonic methods. Furthermore, the Liv-Ex index (www.liv-ex.com), which has became a reference for wine investors, is constructed almost the same way. Another strength of this approach is that the index returns effectively correspond to the ones that would have been achieved by an investor with a well-balanced wine portfolio.

\section{Implementation}

Wines coming from the same estate but from different vintages do not correspond to a unique homogeneous good. This means that we have to consider each Château-vintage's pair separately. This has an important impact because many of these pairs are traded only on rare occasions. Even the greatest wines are not necessarily traded each month. It is therefore crucial to choose appropriate pricing and weighting schemes when it comes to calculating the index levels.

We refer to each wine using the notation $W_{i, j}$, where $i$ corresponds to the Château ( $i \in I=\{1,2, \ldots, 92\})$ and $j$ to the vintage $(j \in J=\{1,2, \ldots, 29\}) .{ }^{14} \mathrm{We}$ further define $P_{W_{i, j}, t}$ and $V_{W_{i, j},}$, which are the price and the trading volume achieved by wine $W_{i, j}$ in month $t$.

The general wine index and the various subindices (see section 3) are defined on the basis of the set of wines $\Theta_{k, I}=\left\{I_{k}, J_{I}\right\}$ that enter into their calculation $\left(I_{k} \subset I\right.$ and $\left.J_{l} \subset J\right)$. The index level at time $t$ is denoted by $S_{t}\left(\Theta_{k, l}\right)$ and is computed as follows:

$$
S_{t}\left(\Theta_{k, l}\right)=\sum_{i}^{l_{k}} \sum_{j}^{J_{l}} X_{W_{i, j},}\left(\Theta_{k, l}\right) \cdot C_{W_{i, j}}\left(\Theta_{k, l}\right) \cdot P_{W_{i, j}, r}
$$

where $X_{W_{i, j},}\left(\Theta_{k, l}\right)$ is the weight that wine $W_{i, j}$ has in the index $\Theta_{k, l}$ in month $t$.

The value of each index in the first period of the sample $(t=1)$ is set to 100. $C_{W_{i, j}}\left(\Theta_{k, l}\right)$ is a correction factor which is computed as follows:

$$
C_{W_{i, j}}\left(\Theta_{k, l}\right)=\frac{S_{t_{0}}\left(\Theta_{k, l}\right)}{P_{W_{i, j}, t_{0}}}
$$

where $t_{0}$ is the month in which a wine $W_{i, j}$ was traded for the first time. This correction ensures that the standardized price of a wine the first time it was traded is equal to the index level in the same month. If a wine has not been traded in a given month, we set its price equal to the last valid observation we have for this wine.

In the case of an equity index, weights are computed on the basis of the free-float but, in the case of wine, the issue is that we do not know how many full bottles remain available

${ }^{14}$ For instance, $W_{1,1}$ corresponds to château Calon Ségur 1945. 
on the market. ${ }^{15}$ Moreover, the fact that there is no centralized market place makes it difficult to get a precise picture of the number of trades. ${ }^{16} \mathrm{We}$ therefore estimate the weights $X_{W_{i, j}, t}\left(\Theta_{k, l}\right)$ from the average trading volume involved by each wine over the last 12 months. That is, the weight $X_{W_{i, j},}\left(\Theta_{k, l}\right)$ of wine $W_{i, j}$ in the index $\Theta_{k, l}$ at period $t$ is the ratio of the average trading volume of $W_{i, j}$ over the past 12 months divided by the cumulated average trading volume of all wines that enter into the index:

$$
X_{W_{i, j}, t}\left(\Theta_{k, l}\right)=\frac{\frac{1}{12} \sum_{\tau=0}^{11} V_{W_{i, j},(t-\tau, t)}}{\sum_{m}^{I_{k}} \sum_{n}^{J_{l}}\left[\frac{1}{12} \sum_{\tau=0}^{11} V_{W_{m, n^{\prime}(t-\tau, t)}}\right]} .
$$

\section{Evolution of the Wine Market from 1996-2007}

\section{A. General Wine Market Index and the Dow Jones}

Figure 1 shows the evolution of the general wine market index and the Dow Jones over the period 1996-2007. The general wine market index is constructed using the prices of wines from all estates and all vintages.

Figure 1

Comparative Evolution of the Wine Market and the Dow Jones from 1996-2007

Evolution of the Wine Index and the DJIA over the period 1996-2007

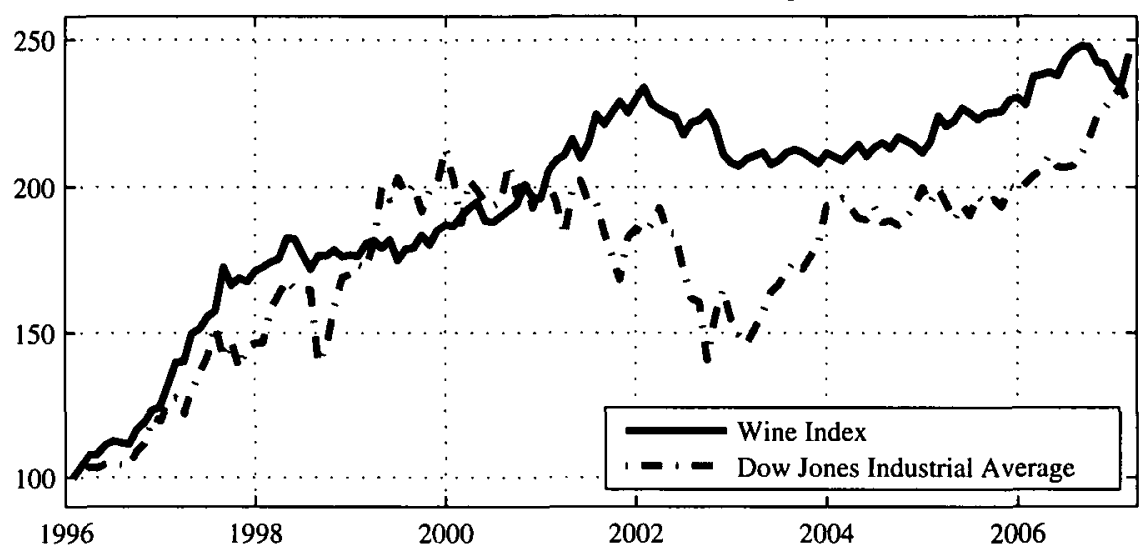

\footnotetext{
15 This number decreases through time and we do not know who is holding a given bottle of wine and is willing to sell it.

${ }^{16}$ There are many ways to sell or to purchase wine: auctions, specialized shops, classified advertisements, etc. Moreover, prices are not necessarily arbitrage-free as the same wine can well trade at a different price from one place to another.
} 
The wine index and the Dow Jones have undergone a strong rise between 1996 and 1998. During the period 1998-2000, both wines and stocks have kept up rising and have achieved almost similar cumulated returns. The burst of the tech bubble and the terrorist attacks in New-York have led the Dow Jones to lose about 7\% in 2001. ${ }^{17}$ Since spring 2002 the wine market has also started to decline but not as sharply as the Dow Jones. In March 2003 after the invasion of Irak, the Dow Jones began to recover from its previous losses. During the period 2003-2005, wine prices remained rather stable. The last two years of the sample have been bullish for both the wine and the stock markets.

The total cumulated return of the wine market index is $145 \%$. In comparison, the Dow Jones has achieved a cumulated return of $127 \%$ over the same period. Risk features also seem to be more favourable for the wine index than for the Dow Jones: the volatility of the wine index averages $8.1 \%$, while the Dow Jones volatility averages more than $15 \%$. Wine returns are right skewed (skewness of 0.50); this is in sharp contrast with the returns on the Dow Jones, which have a skewness of -0.62 . Wine returns also exhibit a very slightly larger excess kurtosis than equity returns (4.38 versus 4.25 ). These results seem more favourable to an investment in wine than those of Fogarty $(2006 \mathrm{~b})$, who concludes that "the risk-return profile of [Australian] wines is broadly comparable to the risk-return profile of Australian equities."

A risk-return analysis is, however, not a sufficient tool for assessing the appeal of wine investment. The costs and benefits of holding wine are of various natures. It has the advantage over other investments that it provides a particular utility to its "owner" as it can be both admired and obviously drunk. However, its consumption implies its destruction. For these reasons, one might expect wine to have a lower return than equity (because of its intrinsic utility) but a higher return than other collectibles (as their consumption does not imply their destruction). Explicit costs are storage costs (between 1 and 2USD per bottle-year) and insurance costs. Obviously wine trading also implies a variety of costs (broker commission, insurance and shipping), which are inherent to the proceeding of wine auctions. They amount to about $10 \%$ of the value of the wine for the buyer and $15 \%$ to $20 \%$ for the seller; though they may vary between various auction houses. Furthermore, with the development of online auctions, they tend to be much lower now (for instance, ebay charges only $3 \%$ to $4 \%$ ). Illiquidity is an implicit but important cost as the liquidation of a cellar might take months. ${ }^{18}$

\section{B. Vintage, Ranking and Rating Defined Indices}

We analyze the price evolution of various subindices defined on the basis of (i) vintages, (ii) ranking, (iii) Parker's rating. We eventually devote some attention to the price appreciation of second wines and so-called garage wines.

\footnotetext{
${ }^{17}$ Over the period January 12001 to September 212001 , the Dow Jones and the Nasdaq 100 respectively lost $23 \%$ and $52 \%$. From March 2000 to the end of 2000 , the Nasdaq had already lost more than 50\%; though, over the same period, the Dow Jones was down by less than $3 \%$.

${ }^{18}$ See also Burton and Jacobsen (2001) for an exhaustive discussion of the costs/benefits associated to the holding and trading of wine.
} 


\section{Vintage defined indices}

Table 1 shows the evolution of eight wine indices constructed on the basis of vintage's quality. We differentiate between wines from the left and the right bank of the Dordogne. ${ }^{19}$ This is because some vintages are better on the right bank than on the left, and vice versa. ${ }^{20}$

\section{Table 1}

Summary Statistics for each Vintage Defined Index

\begin{tabular}{|c|c|c|c|c|c|c|c|c|c|c|}
\hline \multirow[b]{2}{*}{$\begin{array}{l}\text { Vintage's } \\
\text { quality }\end{array}$} & \multicolumn{5}{|c|}{ Left bank } & \multicolumn{5}{|c|}{ Right bank } \\
\hline & \# obs. & $\begin{array}{c}\text { total } \\
\text { return }\end{array}$ & $\begin{array}{c}\text { std. } \\
\text { dev. }\end{array}$ & skewness $^{b}$ & kurtosis $^{b}$ & \# obs. & $\begin{array}{c}\text { total } \\
\text { return }\end{array}$ & $\begin{array}{c}\text { std. } \\
\text { dev." }\end{array}$ & skewness $^{b}$ & kurtosis $^{\mathrm{b}}$ \\
\hline Mediocre & 1,356 & 57.52 & 13.97 & 0.52 & 7.42 & 1,255 & 31.00 & 13.04 & 0.66 & 9.56 \\
\hline Good & 10,722 & 94.80 & 11.07 & 0.50 & 4.92 & 7,239 & 83.25 & 12.15 & 5.10 & 44.04 \\
\hline Very good & 13,354 & 211.20 & 12.56 & 1.19 & 8.19 & 6,582 & 74.65 & 10.71 & 0.43 & 4.23 \\
\hline Outstanding & 24,679 & 220.52 & 10.77 & -0.05 & 3.53 & 11,827 & 104.12 & 12.60 & 0.31 & 5.01 \\
\hline
\end{tabular}

All statsistics are calculated for the period from 1996 to 2007. " Returns and annualized standard deviations are in $\%$. ' Skewness and kurtosis are computed from index log-returns.

It is often argued that only very good to great vintages can be considered as investment grade and, indeed, all vintages considered as outstanding have experienced very strong price increases. The best performers are 1961 (total return of 263\%), 1982 (216\%), $1986(212 \%)$, $1989(301 \%)$ and $1990(246 \%)$. On the other hand, a number of recent vintages have experienced price drops (1995 to 1999 and 2001 to 2002). The reason is probably that these wines were already very expensive when they were released as en primeur. ${ }^{21}$ The evidence also suggests that the most successful vintages for the left bank have experienced higher returns than the best vintages for the right bank. ${ }^{22}$ Volatility is higher for these vintage defined indices than for the general index. This is due to the limited amount of data we have for each specific vintage. The skewness is in general positive and the kurtosis is always above three. ${ }^{23}$ This indicates that the returns on the different indices are not normally distributed.

${ }^{19}$ Wines from the appellations of Saint-Estèphe, Pauillac, Saint-Julien, Pessac and Haut-Médoc belong to the left bank. Wines from the Pomerol and Saint-Emilion appellations belong to the right bank. Cabernet Sauvignon dominates the blend in red wines produced on the left bank, while Merlot tends to predominate on the right bank.

${ }^{20}$ The vintages and their corresponding rating are: 1945 (left bank: 5 and right bank: 5), 1947 (5 and 5), 1955 (4 and 4), 1959 (5 and 5), 1961 (5 and 5), 1966 (4 and 4), 1970 ( 3 and 3), 1975 ( 3 and 4), 1978 ( 3 and 2), 1979 ( 3 and 2), 1981 ( 3 and 3), 1982 (5 and 5), 1983 (4 and 4), 1985 (4 and 3), 1986 (5 and 3), 1988 (3 and 4), 1989 (4 and 4), 1990 (5 and 5), 1993 ( 1 and 2), 1994 (2 and 3), 1995 (4 and 4), 1996 (5 and 3), 1997 (2 and 2), 1998 ( 3 and 5), 1999 ( 3 and 3), 2000 (5 and 5), 2001 ( 3 and 4), 2002 ( 3 and 2), 2003 (5 and 3). ( $1=$ below average, $2=$ average, $3=$ good, $4=$ very good, $5=$ outstanding).

${ }^{21}$ For a discussion of Bordeaux en primeur pricing, see Mahenc and Meunier (2006), who study this issue from a theoretical perspective, and Christensen and Meunier (2006), who analyze empirically this issue and find no evidence suggesting an overpricing.

${ }^{22}$ We have also studied the price appreciation of the different appellations. Pauillac and Saint-Emilion are respectively the best and the worst performers. Detailed results are available from the authors upon request.

${ }^{23}$ The very high levels of skewness (5.10) and kurtosis (44.04) for the good vintages of the right bank is due to the strong price inflation that these wines have experienced during the first two years of the sample. If we exclude the first two years of observations, the skewness and the kurtosis decrease respectively to 0.5 and 9.6. 


\section{Ranking defined indices}

In Table 2, we report summary statistics for the five ranking defined indices. Again, the best investment vehicles ought to be the first growths because their "brand" is known all over the world and because they are supposed to have the best ageing potential. Trading activity is heavily concentrated on the first and second growths. Estates from these two ranking categories have almost achieved the same cumulated return over the period under consideration. They have clearly outperformed the third, fourth and fifth growth estates (by about $65 \%$ to $110 \%$ ). Among the first growth, the best performer is Haut-Brion and the worst is Ausone. For the other ranking categories the best performers are PichonLongueville Baron, Troplong Mondot, La Fleur-Pétrus and Lascombes and the worst performers are respectively L'Evangile, Le Tertre Roteboeuf, Monbousquet and Quinault L'Enclos. The first and fourth growths are characterized by a lower volatility than the other ranking categories. At the exception of the fifth growths (which are characterized by a much larger volatility than any other ranking category), all indices have a volatility below $12 \% .{ }^{24}$ The risk-return profile of the best estates looks very attractive in comparison to the Dow Jones.

Table 2

Summary Statistics for the Ranking Defined Indices

\begin{tabular}{lcrrrrrrr}
\hline Classification & \# Ch. & \# obs. & $\begin{array}{c}\text { total } \\
\text { return }^{\mathbf{a}}\end{array}$ & $\begin{array}{c}\text { max } \\
\text { return }^{\mathbf{a}}\end{array}$ & $\begin{array}{c}\text { min } \\
\text { return }^{\mathbf{b}}\end{array}$ & std. dev. $^{\mathbf{b}}$ & skewness $^{\mathbf{b}}$ & kurtosis $^{\mathbf{b}}$ \\
\hline 1st Growths & 11 & 28,638 & 188.13 & 292.97 & 62.01 & 9.73 & 0.08 & 3.25 \\
2nd Growths & 12 & 20,805 & 191.84 & 202.24 & 14.19 & 10.75 & 0.40 & 5.15 \\
3rd Growths & 13 & 11,092 & 81.49 & 233.95 & -14.20 & 8.33 & 0.95 & 5.64 \\
4th Growths & 13 & 5,589 & 123.36 & 161.52 & -18.55 & 9.15 & 1.62 & 9.82 \\
5th Growths & 27 & 5,847 & 91.07 & 263.48 & -19.34 & 14.11 & 1.14 & 8.56 \\
\hline
\end{tabular}

All statsistics are calculated for the period from 1996 to 2007 . ' Retums and annualized standard deviations are in $\%$. Skewness and kurtosis are computed from index log-returns; max and min returns refer to the best and the worst estate that enters the index.

The fact that less known estates (i.e. third to fifth growths) earn lower returns on average might be justified either by a diversification argument or by the fact that investors in the wine market might be somewhat myopic. That is, if the wine market is segmented such that these wines have a very low correlation with the other wines (and with other financial assets as well), then they should have lower expected returns. ${ }^{25}$ On the other hand, it could also be that investors fail to reward these wines for the exposition to systematic risk factors; this explanation implies that these wines are overpriced.

\footnotetext{
${ }^{24} \mathrm{~A}$ level of $12 \%$ can be considered as a lower boundary for the average volatility of the Dow Jones over the long run.

${ }^{25}$ For instance, this segmentation might be such that less known estates attract a certain category of customers (wine drinkers), while high-end estates attract other types of customers (like speculators or garish people).
} 


\section{Parker's rating defined indices}

Table 3 shows summary statistics for five indices based on Parker's rating. We do not consider wines that have received a rating below 80 as such wines do not attract much attention from wine amateurs and are consequently less frequently traded. Ashenfelter (1989) discusses the so-called "winner's curse", which implies that everyone wants to buy the wines with the highest number of Parker's points. We therefore expect to find a positive relationship between rating and price appreciation. ${ }^{26}$

Table 3

Summary Statistics for the Rating Defined Indices

\begin{tabular}{rcccccc}
\hline $\begin{array}{l}\text { Parker's } \\
\text { points }\end{array}$ & $\begin{array}{c}\text { \# wines in } \\
\text { index }\end{array}$ & $\begin{array}{c}\text { \# obs in } \\
\text { index }\end{array}$ & total return $^{\mathbf{a}}$ & std dev $^{\mathbf{a}}$ & skewness $^{\mathbf{b}}$ & kurtosis $^{\mathbf{b}}$ \\
\hline 100 & 40 & 8,892 & 249.33 & 14.66 & 0.97 & 5.81 \\
$96-99$ & 105 & 14,944 & 194.49 & 10.29 & 0.46 & 3.88 \\
$93-95$ & 216 & 19,239 & 73.41 & 9.53 & 0.79 & 5.54 \\
$90-92$ & 313 & 19,294 & 47.70 & 8.23 & 2.88 & 24.00 \\
$80-89$ & 477 & 12,563 & 113.22 & 8.53 & 0.18 & 4.23 \\
\hline
\end{tabular}

All statsistics are calculated for the period from 1996 to 2007. "Retums and annualized standard deviations are in \%. 'Skewness and kurtosis are computed from index log-returns.

The index containing the wines that have been rated 100 by Robert Parker achieves a spectacular cumulated return of $249 \%{ }^{27}$ This amounts $12 \%$ on an annual basis. This index outperforms the general wine index and the Dow Jones. Its annualized standard deviation $(14.66 \%)$ is higher than for the general index but very comparable to the volatility of the Dow Jones. When looking at the other rating categories, one may also notice that the best wines are traded much more frequently than the others and achieve higher returns. Skewness and kurtosis are not consistent with a normal distribution. The volatility of returns seems to be larger for the wines that have received the best grades from Parker. This might be due to the fact that we have less observations for this index. Interestingly, the index containing wines rated between 80 and 89 has achieved a spectacular cumulated return. In order to understand more precisely the origins of this performance, we split this category into two subcategories, which contain wines rated between 80 and 85 and between 86 and 89 . The cumulated return on the first subcategory is about $24 \%$, while that on the second category exceeds $130 \%$. Overall the best performer is La Mission Haut Brion 1989 (with a cumulated return of 529\%); this estate is classified as first growth.

\footnotetext{
26 Jones and Storchmann (2001), Ashenfelter (1989) and Lecocq and Visser (2006) use ratings from a jury but do not find any significant relationship between prices and ratings.

${ }^{27} 50$ wines from Bordeaux have been rated 100 by Parker. These wines come from 18 different estates. Though we have enough data only for 40 wines (some estates and some vintages do not attract enough trading volume to get reliable return estimates). From our dataset, six vintages from La Mission Haut Brion got this score; LafiteRothschild, Lafleur and Pétrus follow with five "perfect" wines.
} 


\section{Second wines and "garage" wines}

During the last few years, second wines have attracted much interest. This is primarily due to the fact that first growths have become extremely expensive; as a consequence many amateurs have decided to switch to the second wines of these estates. Another trend is the birth of so-called "garage wines." This name comes from the fact that many of these estates are recent and have a very restraint production; some of these wineries look like garages. There is an increasing number of such new wineries in particular in Saint-Emilion. The underlying idea is "small quantities but high quality." The many detractors of these wines would reformulate this marketing formula to an even simpler credo: "highly priced and speculative wines."

We have only few observations for these categories (1,202 for the second wines and 3,841 for the garage wines) and most trades have taken place after year 2000 , which makes a performance analysis difficult. We therefore concentrate on the period 2000-2007. Interestingly, both categories of wines have achieved negative returns over this period: $32.05 \%$ for the second wines and $-13.18 \%$ for the garage wines. A possible explanation for this observation is that garage wines might be too expensive when they are released $e n$ primeur, leading their prices to decline progressively once they arrive on the market.

\section{Relationship Among Wines from Different Ranking Categories}

In this section we study the cross-relationships among the ranking indices. In a first step, we analyze whether they follow a single long-run trend or not. Then, we check if some causality relationships (in the sense of Granger) might also exist among these indices. Finally, we compare the evolution of the various indices in the short-run using a correlation analysis. As we have less observations for the third, fourth and fifth growths, we decided to merge them into a unique category. ${ }^{28}$ This is in order to avoid spurious results because of low liquidity. This is also a reasonable classification from the point of view of wine amateurs, who usually refer either to the first growths or the so-called super seconds (the second growths in our classification) and consider all other classified Bordeaux as followers.

\section{A. Long-Run Cross-Relationship}

We first run an augmented Dickey-Fuller (ADF) test to analyze whether the series are stationary or not. The specification is as follows:

$$
S_{g, t}=\alpha+\beta t+\gamma s_{g, t-1}+\sum_{i=1}^{p} \gamma_{i} \Delta s_{g, t-i}+u_{t},
$$

${ }^{28}$ This strategy also mitigates possible multicollinearity problems that might appear when studying the series in a multivariate framework. 
where $S_{g, t}$ is the log of the index level at time $t$ and $g$ designates the growth category; $\alpha$ is a constant, $\beta t$ is the time-trend and $\sum_{i=1}^{p} \gamma_{i} \Delta s_{g, t-i}$ is used to account for possible autocorrelation in the residuals $u_{t}$. As we do not find much trace of autocorrelation in $u_{t}$, we set $p$ to 1 . The ADF test is run on $\gamma$. The $H 0$ hypothesis is that $\gamma \geq 1$; this corresponds to the case in which there is a unit root in the time-series. The critical values are obtained by simulation (see Hamilton (1994) for details). The evidence demonstrates that we cannot reject the null hypothesis of a unit root in all three wine index series. ${ }^{29}$ This is not a surprise as it is well known that most economic and financial indices are non-stationary.

The next step is to test if the series are cointegrated. The purpose of this test is to analyze whether there exists a long-run equilibrium relationship between the different wine indices or not. If all categories of wines share the same clientele, we are likely to find a unique cointegration relation between the indices. Nevertheless, it might be that the highly reputed first growth estates follow a different trend than lesser known estates. We model the three series in a vector error correction model (VECM):

$$
\Delta s_{t}=\mu+\sum_{i=1}^{p-1} \Phi_{i} \Delta s_{t-i}+\Pi s_{t-1}+\varepsilon_{t},
$$

where $s_{t}=\left[s_{1, t} s_{2, t} s_{3, t}\right]$. The order $p$ of the vector autoregression has been chosen on the basis of the Akaike and Schwartz information criteria. Both criteria indicate that $p=1$ is appropriate. The next step is to identify the rank $r$ of matrix II. Three cases can be identified. If the matrix is of full rank $(r=3)$, this indicates that all series are stationary. We can discard this case as all series have already been found to be I(1). The opposite case, in which the matrix is of rank zero $(r=0)$, corresponds to a situation in which all series are I(1) but there is no cointegration relation. The last case is when the matrix is singular but $r \geq 0$, this is the cointegration case and $r$ indicates the number of cointegration relations.

The results for the trace and the eigenvalue test statistics are reported in Table 4. Both statistics indicate that there is indeed a single cointegration relationship that links the different indices together. ${ }^{30}$ This result supports the assumption that the three wine indices have a common trend. Nevertheless, given the limited time span of our dataset, it is difficult to conclude whether the wine indices are linked together in the long term or just in the mid term.

\section{B. Lead-Lag Relationships}

We make use of the VECM framework to study the causality relations (in the sense of Granger), which might exist across the different wine indices. This implies imposing and

\footnotetext{
${ }^{29}$ The test statistics are between -0.30 and -0.45 for all indices. The critical values according to the length of our sample are respectively $-3.16,-3.45$ and -4.00 at the $10 \%, 5 \%$ and $1 \%$ percentile.

${ }^{30}$ In this case, $\Pi s_{t-1}$ can be rewritten as $\beta Z_{t-1}$, where $z_{t-1}$ is the unique (given that $r=1$ ) linear combination of the three wine indices $\left(\alpha^{\prime} s_{t-1}\right)$ that results in a stationary series.
} 
Table 4

Results of the Johansen Test of Cointegration

\begin{tabular}{lccc}
\hline $\begin{array}{l}\text { \# cointegration } \\
\text { relationships }\end{array}$ & Eigenvalue & $\begin{array}{c}\text { Max-Eigenvalue } \\
\text { statistic }\end{array}$ & Trace statistic \\
\hline$\leq 0$ & 0.1907 & $26.23^{* *}$ & $40.83^{* *}$ \\
$\leq 1$ & 0.1096 & 14.40 & 14.60 \\
$\leq 2$ & 0.0016 & 0.20 & 0.20 \\
\hline
\end{tabular}

***** and * denote significativity at the $99 \%, 95 \%$ and $90 \%$ confidence level.

testing some restrictions on the elements of the $\Phi_{i}$ matrices. As the number of lags to be used in the vector autoregression has been set to 1 (see section 4.1), we only have to consider the $\Phi_{1}$ matrix, which might be developed as follows:

$$
\Phi_{1}=\left[\begin{array}{lll}
\phi_{11}^{(1)} & \phi_{12}^{(1)} & \phi_{13}^{(1)} \\
\phi_{21}^{(1)} & \phi_{22}^{(1)} & \phi_{23}^{(1)} \\
\phi_{31}^{(1)} & \phi_{32}^{(1)} & \phi_{33}^{(1)}
\end{array}\right]
$$

We compare the explanatory power of a model specification in which all the elements of the $\Phi_{1}$ matrix are estimated with a restricted model in which we impose one of the elements of the matrix to be zero, i.e. $\phi_{l k}^{(1)}=0$. If the mean squared errors (MSE) of both models are not significantly different, we will conclude that variable $k$ fails to Grangercause variable $l$ (see, e.g., Hamilton, 1994).

Since first growths attract much of the attention of wine lovers and wine investors, we suspect à priori that the causality relation, if any, should run from this category to the other ranking categories. Furthermore, wines from less known estates are traded only rarely and are thus likely to be less reactive to changes in the global wine market. Studying causality in the context of financial asset prices necessarily implies the questions of predictability and arbitrage. The causality relation, if any, should not be too strong, otherwise it would become possible to make money without taking much risk (a "free lunch" in the financial jargon) and one would have to conclude that the wine market is inefficient.

The results indeed indicate that some of the elements of the $\Gamma_{1}$ matrix are significantly different from zero at standard levels: $\phi_{1}^{(1)}=-0.3144$ (p-value: $\left.<0.01\right), \phi_{1}^{(1)}=-0.1611$ $(0.04)$ and $\phi_{33}^{(1)}=0.2155(0.04) .{ }^{31}$ The fact that $\phi_{11}^{(1)}$ is negative suggests first growths tend to overreact in the short-run and then correct back. The returns on third to fifth growths are also influenced by their own lagged realizations but the sign of the correlation is positive, suggesting that there is some delay in the adjustment of the prices of these wines. Furthermore, one may notice that past returns on the first growths have a negative impact on subsequent returns on third to fifth growths. This causality direction is inline with the

\footnotetext{
${ }^{31}$ In order to spare space, detailed results are not reported here but they are available from the authors upon request.
} 
previous discussion but the sign of the coefficient is a bit more surprising (one would have expected a positive coefficient).

The standard VECM-Granger-causality approach is only able to identify linear effects. Given the non-trivial distribution of the returns on the different wine indices, some, more complicated, non-linear lead-lag effects may also link the different indices together. In order to check whether such relations exist, we make use of a non-parametric Granger causality test. We use the test specification of Diks and Panchenko (2006) (see also Baek and Brock, 1992; Hiemstra and Jones, 1994). The test is applied to the residuals $\varepsilon_{\text {, from the }}$ previous VECM, see Equation (4). As suggested by Diks and Panchenko (2006), we first uniformize the data. The test is then applied on a bivariate basis; that is, we analyze the causality among each possible pair of series. The bandwidth is set to two standard deviations and the number of lags to one. As a cross-check, we also consider a bandwidth of 1.5 and 2.5 standard deviations and up to two lags.

A significant non-linear autocorrelation can be found in the three indices. This result holds for all test specifications (i.e. for 1 and 2 lags and for bandwidths of 1.5, 2 and 2.5 standard deviations). We also find a nonlinear causality running from first to third to fifth growths and from second to first growths. These results hold for most (not all) test specifications are less significant. It also seems that lesser estates (third to fifth growths) might lead the more renowned Châteaux but this result holds only when we consider at least two lags. ${ }^{32}$

\section{Short-Run Cross-Relationship}

We eventually estimate the short-run cross-dependencies between the various index returns series. Once again, we consider the residuals $\varepsilon_{t}$ from the previous VECM regression (4). Because they are not normally distributed, we use the non-parametric Spearman's rank correlation coefficient. ${ }^{33}$ These correlation coefficients are informative about the diversification possibilities that the different indices offer. Low or even negative correlations among the different subindices may allow the construction of a more efficient wine portfolio (i.e. a portfolio with a lower volatility). The highest correlation $(0.54)$ is found for the relation between second and third to fifth growths. The correlation between first and second growths amounts to 0.43 , while the correlation between first and third to fifth growths is lower (0.28). These results, while leaving some space for diversification, clearly show that shocks in the wine market have a direct impact on all wine categories.

We also estimate time-varying correlations among the different wine indices. This should give some insights on the stability of the relations that link the indices together in the short run. A multivariate GARCH model is fitted to the residuals of the VECM regression (4). We

\footnotetext{
32 Detailed results can be obtained from the authors upon request.

${ }^{33}$ As a matter of comparison, we also estimated standard Pearson correlation coefficients. The results were very similar.
} 
opt for the dynamic conditional correlation (DCC) model of Engle (2002) because it explicitly models the time-varying correlations. ${ }^{34}$ It is also tractable and relatively parsimonious in comparison with other multivariate GARCH models. The time-varying correlations are reported in Figure 2. One may observe that the correlation between the first and the second growths has remained remarkably stable over the period under consideration. The other two time-series of dynamic correlations are more erratic. Nevertheless, the correlation between first and third to fifth growths has always been lower than the correlation between first and second growths. All in one, the correlation among first and third to fifth growths displays a very similar pattern to the correlation between second and third to fifth growths, although the latter has become more significant in the last two years of the sample.

Figure 2

Dynamic (Time-Varying) Correlations Between Different Wine Rankings

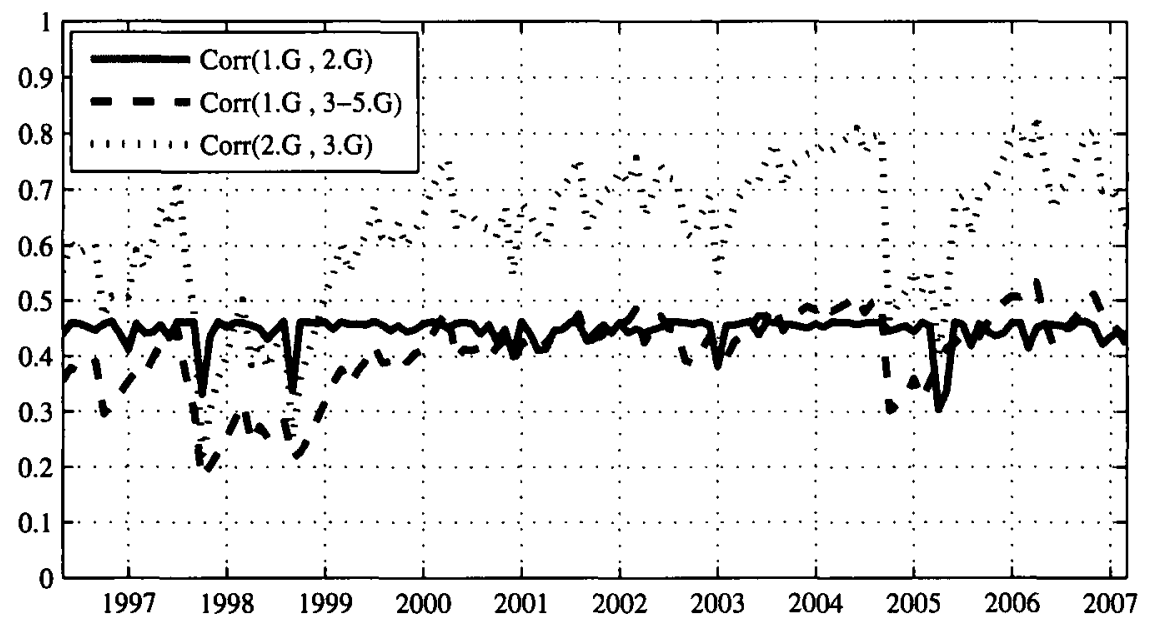

\section{Improving Diversification Through Investing in Wines}

\section{A. Mean-Variance Analysis}

We analyze in a standard mean-variance framework if investing in wines might be a way of improving the diversification of an equity portfolio. In order to mitigate the impact of non-synchroneous trading, returns are sampled every quarter and expected returns and variance are computed accordingly. We derive the efficient frontier for four different cases. We first consider only equities and we then progressively extend the universe of assets by including first art works ${ }^{35}$ and then various wine categories. This permits to

\footnotetext{
34 We skip the technicalities. See, e.g., Tsay (2002) and Jondeau, Poon and Rockinger (2007) for an introduction and an up-to-date discussion about the modelling of multivariate financial time-series.

${ }^{35}$ We gather these data from the website www.artprice.com.
} 
observe the additional effect that these assets have on the efficient frontier. The results are reported in Figure $3 .{ }^{36}$ The risk-free rate corresponds to the yield of a treasury bond with a constant maturity of 1 year.

Figure 3

Efficient Frontier for Different Asset Classes: Equities ('E"), Art Works ("A") and Wine ("W")
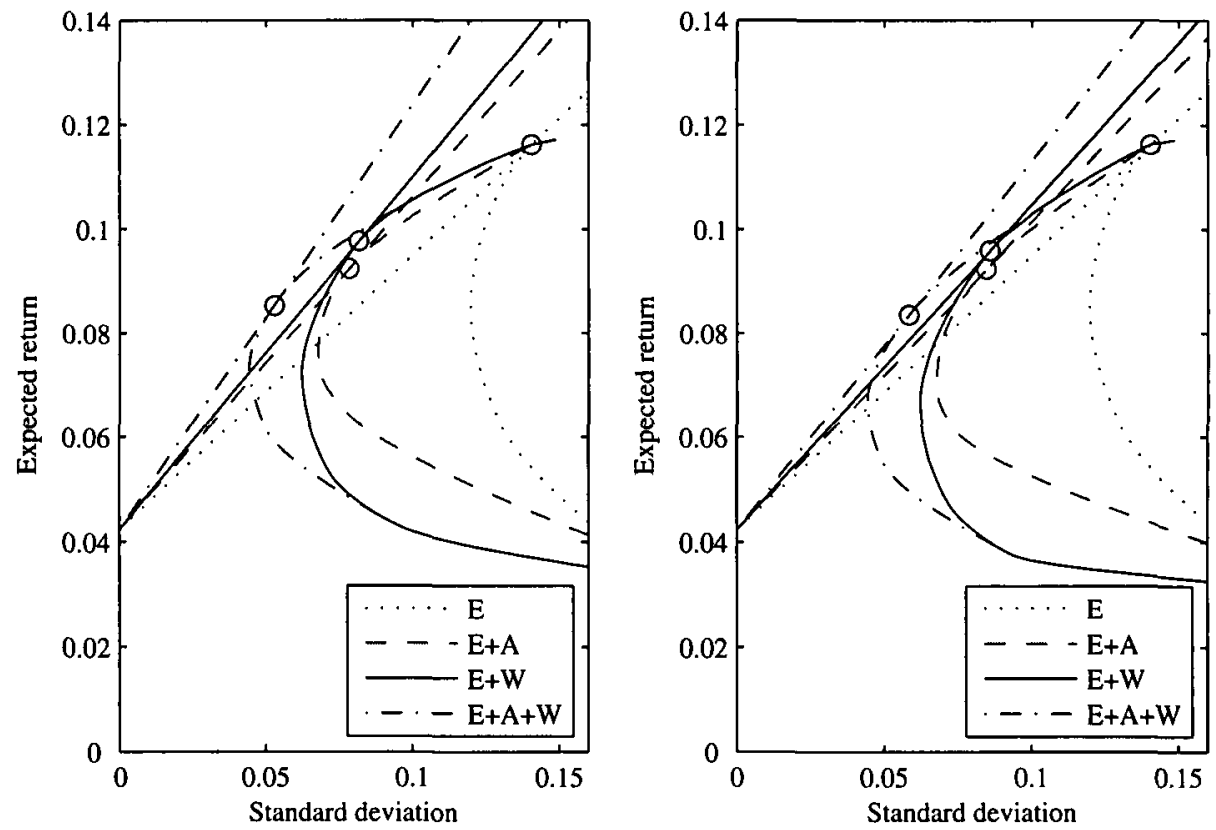

Note: The left panel is based on raw retums, while the right panel reports the efficient frontier for cost-adjusted returns.

In the first case (denoted by "E" in the Figure), we derive the efficient line using the following assets: ten US sectorial indices ${ }^{37}$, the MSCI luxury index and the MSCI world index (excluding the USA). ${ }^{38}$ This reflects the efficient portfolios for an investor, who focuses on equities only and diversifies across sectors and countries. In the second case ("E+A"), an art index is added to the spectrum of asset classes. For the third case ("E+W"), we study the impact of adding wines to an equity portfolio. The last case ("E+A+W") reports the optimal portfolios for an investor, who diversifies across equities, art works and wines. As wine trading is associated with both transaction costs and periodic costs (insurance and storage), we also calculate the efficient portfolio after having applied a discount

\footnotetext{
${ }^{36}$ We show only the efficient frontiers for the ranking-defined wine indices. Results for the rating-defined indices are very similar and are available from the authors upon request.

${ }^{37}$ These sectors are: oil and gas, basic resource, industrial goods and services, consumer goods, health care, consumer services, telecom, utilities, financials and technology.

${ }^{38}$ Data have been obtained from Datastream.
} 
of $20 \%$ on the final price reached by each wine ${ }^{39}$ and a discount of $1 \%$ per year on their average returns. These numbers seem to be rather conservative to us. To be fully consistent, we apply the same discount on the returns on art works. ${ }^{40}$ Corresponding efficient lines are reported in the left panel of Figure 3.

It is apparent from the Figure that adding collectibles like wines and arts to an equity portfolio permits to achieve a better diversification. Notably, the standard deviation of the optimal portfolio becomes much lower, thanks to the low correlations of wines and arts with other assets. The fact that the expected returns are also broadly comparable across the asset classes obviously helps achieving such a result. Furthermore, the impact of taking into account the costs involved by holding and selling wines and art works seems to be quite limited: the expected return of the optimal portfolio is a bit lower and its variance increases slightly. These results are perfectly in line with those of Fogarty (2007) who shows that, even after taking into account transaction costs, investing in wines allows significant risk-reduction benefits. Sanning, Shaffer and Sharratt (2008) arrive at an essentially similar conclusion using another approach (CAPM and Fama-French three factors model). Their results indicate that wine returns covary only minimally with the returns on various factors of systematic risk. Consequently, an investment in wine is rewarded by positive risk-adjusted returns.

Table 5 shows the weighting scheme across the different asset categories for the various optimal portfolios. PF0 is for the case in which the portfolio is fully invested in equities. The left panel (PF1a to PF2b) is for the five ranking defined wine indices and the right panel (PF3a to PF4b) is for the rating defined indices. PFla is invested in both equities and wines; PFIb is constructed in a similar fashion but it also takes into account the impact due to the costs incurred by an investment in wines. PF2a also incorporates art works in the portfolio; PF2b accounts for the costs incurred by an investment either in wines or in art works. We observe that both wines and arts have interesting properties in terms of diversification as they are highly weighted in the optimal portfolio. When wine indices based on ranking are considered, about $42 \%$ of the optimal portfolio has to be invested in first, second and fourth growths. Similarly, $38 \%$ of the optimal portfolio has to be invested in wines when we employ rating defined wine indices. The most heavily weighted wines in this portfolio are the wines rated 96 or above by Parker. If we do not take into account the costs incurred by an investment in wine (PF2a), wines rated in the range 80 to 89 may also provide a good diversification because of their low correlations with other wine categories and with other asset classes, in particular with art works. A significant part of the optimal portfolios has to be invested in art work, about $37 \%$ to $41 \%$ depending on the portfolio considered. As already observed from Figure 3, the discount that we have applied on wine (and art) returns has a minor impact on the optimal portfolio. Furthermore, the weights remain mostly unaltered.

\footnotetext{
${ }^{39}$ That is, we make the implicit assumption that wine investors have sold their wines in the last period of the sample.

${ }^{40}$ Insurance costs might indeed be very large for art works and transaction costs are also close to or even larger than $20 \%$.
} 
Table 5

Optimal Portfolios for Different Asset Classes

\begin{tabular}{lcrrrrrrrr}
\hline & \multicolumn{4}{c}{ Ranking defined indices } & \multicolumn{3}{c}{ Rating defined indices } \\
\hline & \multicolumn{1}{c}{ PF0 } & PF1a & PF1b & PF2a & PF2b & PF1a & PF1b & PF2a & PF2b \\
Exp. ER & 7.40 & 5.54 & 5.36 & 4.30 & 4.12 & 6.04 & 5.93 & 4.51 & 4.57 \\
Std. dev. & 14.06 & 8.19 & 8.61 & 5.28 & 5.84 & 8.97 & 9.43 & 5.62 & 6.47 \\
Sharpe & 0.53 & 0.68 & 0.62 & 0.82 & 0.71 & 0.67 & 0.63 & 0.80 & 0.71 \\
Wines 1 & - & 41.45 & 34.24 & 21.66 & 21.14 & 25.64 & 24.45 & 13.44 & 14.76 \\
Wines 2 & - & 26.46 & 25.04 & 17.26 & 19.20 & 34.38 & 31.69 & 22.04 & 23.71 \\
Wines 3 & - & 0.00 & 0.00 & 0.00 & 0.00 & 0.00 & 0.00 & 0.00 & 0.00 \\
Wines 4 & - & 0.16 & 0.00 & 6.97 & 1.71 & 0.00 & 0.00 & 0.00 & 0.00 \\
Wines 5 & - & 0.00 & 0.00 & 0.00 & 0.00 & 3.22 & 0.00 & 9.23 & 0.00 \\
Equities & 100.00 & 31.92 & 40.72 & 13.73 & 20.60 & 36.77 & 43.86 & 13.95 & 23.47 \\
Arts & - & - & - & 40.38 & 37.35 & - & - & 41.35 & 38.06 \\
\hline
\end{tabular}

For each optimal portfolio, the expected excess retum (in \%), standard deviation (in \%), Sharpe ratio and the weights (in $\%$ ) to be invested in the different asset categories are reported. Wines categories 1 to 5 refer to the first to the fifth growths in the left panel and to to the wines with the best (100) Parker's rating to the wines with the worst (80-89) Parker's rating in the right panel. PF1a (PF2a) and PF1b (PF2b) are built on the basis of, respectively, raw and cost-adjusted returns on wines.

\section{B. Mean-Variance-Skewness-Kurtosis Analysis}

In this section, we derive the optimal allocation between wines and equities ${ }^{41}$ in a meanvariance-skewness-kurtosis framework. There are at least two major justifications for incorporating higher moments into the analysis:

(1) Wine and equity returns have a non-trivial joint distribution. Their marginal distributions are clearly non-normal and their higher moments are dissimilar.

Notably, wines seem to have a positive skewness and a slightly larger kurtosis than equities. Furthermore, wines have rather low correlations with equities. As such it might also prove useful to study how their higher comoments are related.

(2) The assumptions implied by the mean-variance paradigm are very restrictive. There are many claims suggesting that investors are also affected in their utility by the higher moments of the returns distribution (see Jondeau, Poon and Rockinger, 2007). Investors typically like portfolios with positive skewness and dislike portfolios that have a large kurtosis. Hence, a more realistic approach to optimal allocation would include beneath the usual set of objectives (i.e. maximization of the excepted return and minimization of the variance) the maximization of the skewness and the minimization of the kurtosis.

${ }^{41}$ Returns on art works are only available on a quarterly basis. This makes it difficult to get reliable estimates of their higher co-moments with wines and equities. We therefore do not include them in the analysis. 
In order to deal with the difficult task to jointly maximize expected returns and skewness and minimize variance and kurtosis, we use a polynomial goal programming (PGP) model (see Lay, Yu and Wang (2006) and Davies, Kat and Lu (2009) for a full description). That is, we maximize the following expression:

$$
Z=\left|1+\frac{E^{*}-E_{w}}{E^{*}}\right|^{\lambda_{1}}+\left|1+\frac{V_{w}-V^{*}}{V^{*}}\right|^{\lambda_{2}}+\left|1+\frac{S^{*}-S_{w}}{S^{*}}\right|^{\lambda_{3}}+\left|1+\frac{K_{w}-K^{*}}{K^{*}}\right|^{\lambda_{4}},
$$

where $E, V, S$ and $K$ stand for the expected return, variance, skewness and kurtosis of the portfolio. We employ returns in excess to the risk-free interest rate (as in Lay, Yu and Wang, 2006). The symbol * denotes the optimal value for each moment independently of the others (i.e. by optimizing only this moment leaving the others free) and the symbol $w$ denotes the value of each moment when the weighting matrix is $W=w$. The parameters $\lambda_{1}, \lambda_{2}, \lambda_{3}$ and $\lambda_{4}$ allow to give more or less importance to the deviation of each moment from its optimal value. They can be considered as a measure of the investor preferences for each moment. If $\lambda_{3}$ and $\lambda_{4}$ are set to zero, the problem reduces to the standard mean-variance paradigm. Finally, we also impose two conditions on $w: w I=1$ and $w \geq 0$ (short-selling is prohibited).

Tables 6 and 7 show how each asset is weighted in the optimal portfolios for various sets of investor preferences. Table 6 is for wine indices defined on the basis of wine ranking, while Table 7 is for rating defined wine indices. PF1 is built on the basis of expected return and variance only; it serves as a benchmark. PF2 to PF4 show the results when we include the skewness (PF2), the kurtosis (PF3) and both the skewness and the kurtosis (PF4) into the analysis.

When investors care about skewness, the expected return of the portfolio is reduced, while both its variance and its kurtosis are increased (comparison of PF2 with PF1). The part of the portfolio that has to be invested in wines (arts) becomes much larger (smaller). Moreover, first and second growths (or wines rated 100, in Table 7) are less heavily weighted relatively to fourth and fifth growths (wines rated between 90 and 92). The impact of taking the kurtosis into account (but without accounting for the skewness, see PF3) depends on whether we consider ranking or rating defined indices. In the first case, the kurtosis is reduced but the other three moments of the return distribution do not change much; the allocation also remains essentially similar except the fact that second growths are less heavily weighted than in PF1. In the second case (i.e. when considering rating defined indices), the expected return and the variance of the portfolio go down and the part of the portfolio invested in the best wines strongly increases. When both the skewness and the kurtosis are considered (PF4), $\lambda_{3}$ and $\lambda_{4}$ tend to cancel each other out as the resulting portfolio has only slightly lower expected return and variance than PF1. The proportion of arts and equities in the optimal portfolio is reduced in favour of first, second and fourth growths (Table 6) and wines rated 100 (Table 7).

PF5 to PF8 focus on the optimal allocation for investors who have a strong preference for expected return (PF5), variance (PF6), skewness (PF7) or kurtosis (PF8). PF5 is 
Table 6

Portfolio Allocation and Summary Statistics for Various Investor Preferences over the Moments of the Portfolio Return Distribution

Wine indices based on ranking

\begin{tabular}{lrrrrrrrr}
\hline Ranking & PF1 & PF2 & PF3 & PF4 & PF5 & PF6 & PF7 & PF8 \\
\hline$\lambda_{1}$ & 1 & 1 & 1 & 1 & 2 & 1 & 1 & 1 \\
$\lambda_{2}$ & 0.25 & 0.25 & 0.25 & 0.25 & 0.25 & 0.5 & 0.25 & 0.25 \\
$\lambda_{3}$ & 0 & 1 & 0 & 1 & 1 & 1 & 2 & 1 \\
$\lambda_{4}$ & 0 & 0 & 0.25 & 0.25 & 0.25 & 0.25 & 0.25 & 0.5 \\
$E_{w}$ & 4.41 & 2.88 & 4.25 & 3.96 & 7.42 & 3.71 & 2.55 & 3.91 \\
$V_{w}$ & 4.82 & 6.33 & 4.84 & 4.77 & 12.81 & 4.37 & 6.93 & 4.86 \\
$S_{w}$ & -0.11 & 3.01 & -0.09 & 0.73 & -0.38 & 0.52 & 3.30 & 0.12 \\
$K_{w}$ & 2.90 & 15.94 & 2.14 & 3.24 & 2.64 & 2.98 & 17.75 & 1.97 \\
1st Growths & 22.56 & 14.39 & 23.88 & 25.92 & 0.00 & 21.95 & 12.52 & 35.52 \\
2nd Growths & 14.97 & 6.40 & 4.57 & 22.95 & 13.27 & 16.28 & 3.93 & 7.08 \\
3rd Growths & 0.00 & 4.25 & 0.00 & 0.00 & 0.00 & 0.00 & 10.35 & 0.00 \\
4th Growths & 11.67 & 44.48 & 17.51 & 15.21 & 0.00 & 19.34 & 45.98 & 11.22 \\
5th Growths & 0.00 & 12.10 & 0.00 & 0.00 & 0.00 & 0.00 & 14.15 & 0.00 \\
Equities & 11.26 & 6.92 & 15.51 & 5.92 & 86.73 & 6.20 & 5.85 & 11.62 \\
Arts & 39.53 & 11.46 & 38.54 & 29.99 & 0.00 & 36.23 & 7.22 & 34.56 \\
\hline
\end{tabular}

PF1 to PF8 have been estimated for a variety of investor preferences, which are represented by the values attributed to $\lambda_{1}, \lambda_{2}, \lambda_{3}$ and $\lambda_{4}$. For each portfolio, the expected return $\left(E_{w}\right.$, in $\left.\%\right)$, volatility $\left(V_{w}\right.$, in $\left.\%\right)$, skewness $\left(S_{w}\right)$, kurtosis $\left(K_{w}\right)$ and the weights (in $\left.\%\right)$ to be invested in the various asset categories are reported.

characterized by higher expected return than in the base case (PF4) but this is at the cost of a much larger volatility. This portfolio has to be fully invested in second growths (respectively, wines rated between 80 and 89 ) and equities. On the other hand, the impact of taking a larger value for $\lambda_{2}$ is less pronounced (PF6): the expected return and the variance are only moderately reduced. The allocation among the different asset classes remains mostly unaffected. PF7 displays much larger variance, skewness and kurtosis than PF4. When we consider rating based wine indices, PF7 also has a much larger expected return than PF4. Furthermore, the part of the portfolio invested in first and second growths (respectively wines rated at or above 90) is dramatically reduced, while third to fifth growths (wines rated below 90 in Table 7) goes up to about $75 \%$ (respectively 70\%, Table 7). Giving more importance to the kurtosis by increasing $\lambda_{4}$ (PF8) leads to a portfolio with rather similar features as PF4 for rating defined indices. Nevertheless, the differences between PF4 and PF8 are more important when we look at Table 6 (ranking defined indices) as the part to be invested in first growths, equities and art works increase, while the proportion of second and fourth growths decrease. This results in lower skewness and kurtosis. 
Table 7

Portfolio Allocation and Summary Statistics for various Investor Preferences over the Moments of the Portfolio Return Distribution.

Wine indices based on rating

\begin{tabular}{lrrrrrrrr}
\hline Rating & PF1 & PF2 & \multicolumn{1}{c}{ PF3 } & PF4 & PF5 & PF6 & PF7 & PF8 \\
\hline$\lambda_{1}$ & 1 & 1 & 1 & 1 & 2 & 1 & 1 & 1 \\
$\lambda_{2}$ & 0.25 & 0.25 & 0.25 & 0.25 & 0.25 & 0.5 & 0.25 & 0.25 \\
$\lambda_{3}$ & 0 & 1 & 0 & 1 & 1 & 1 & 2 & 1 \\
$\lambda_{4}$ & 0 & 0 & 0.25 & 0.25 & 0.25 & 0.25 & 0.25 & 0.5 \\
$E_{w}$ & 4.54 & 4.29 & 3.89 & 3.73 & 6.79 & 3.46 & 5.55 & 3.64 \\
$V_{w}$ & 5.07 & 5.30 & 4.56 & 4.44 & 10.48 & 4.22 & 10.39 & 4.54 \\
$S_{w}$ & 0.05 & 0.78 & 0.14 & 0.37 & 0.45 & 0.36 & 1.38 & 0.24 \\
$K_{w}$ & 2.69 & 3.41 & 1.81 & 2.01 & 3.43 & 2.02 & 4.80 & 1.71 \\
100 points & 16.75 & 16.35 & 30.51 & 31.87 & 0.00 & 34.95 & 0.00 & 33.91 \\
$96-99$ points & 0.00 & 0.00 & 0.00 & 0.00 & 0.00 & 0.00 & 0.00 & 0.00 \\
$93-95$ points & 0.00 & 0.00 & 0.00 & 0.00 & 0.00 & 0.00 & 0.00 & 0.00 \\
$90-92$ points & 19.46 & 39.06 & 14.68 & 20.61 & 0.00 & 18.32 & 10.50 & 16.55 \\
$80-89$ points & 13.73 & 11.03 & 8.96 & 7.06 & 60.79 & 6.97 & 74.17 & 7.97 \\
Equities & 11.03 & 5.05 & 9.14 & 7.04 & 39.21 & 5.58 & 9.05 & 7.76 \\
Arts & 39.02 & 28.51 & 36.71 & 33.42 & 0.00 & 34.18 & 6.28 & 33.81 \\
\hline
\end{tabular}

PF1 to PF8 have been estimated for a variety of investor preferences, which are represented by the values attributed to $\lambda_{1}, \lambda_{2}, \lambda_{3}$ and $\lambda_{4}$. For each portfolio, the expected retum $\left(E_{w}\right.$, in $\left.\%\right)$, volatility $\left(V_{w}\right.$ in $\left.\%\right)$, skewness $\left(S_{w}\right)$, kurtosis $\left(K_{w}\right)$ and the weights (in $\left.\%\right)$ to be invested in the various asset categories are reported.

Results from Tables 6 and 7 indicate that the allocation among the different assets almost always gives priority to wines. On average about $20 \%$ of the portfolio has to be invested in the best wines (i.e. first growths in Table 6 and wines rated 100 in Table 7). Depending on the preferences of the investors, their weight varies between $0 \%$ and $30 \%$ (rating defined indices) to $35 \%$ (ranking defined indices). When the primary focus of the investors is the expected return (see PF5 in the Tables) of their portfolio (and, to a lesser extent, its skewness-see PF7), the proportion invested in these wines dramatically decrease. The situation is reversed when the investors want to reduce the volatility and the kurtosis of their portfolio; in this case, a substantial part of the portfolio has to be invested in the best wines. Second growths are especially attractive in the perspective of either increasing the expected return of the portfolio or reducing its volatility. On the other hand, investing in lesser wines (i.e. third to fifth growths in Table 6 and wines rated at or below 92 in Table 7) permit to increase both the skewness and, to a lesser extent, the expected return of the portfolio. Thus, even if these categories do not offer the most attractive risk-return profile, they 
still help improving the portfolio diversification by increasing its skewness. All in one, an investor who wants to increase the expected return of his portfolio, irrespective of its variance, has to invest a larger amount into equities. On the other hand, if he chooses to invest more aggressively in wines, he will see the skewness of his portfolio increases.

Our results indicate that there are several tradeoffs among the different moments of the portfolio returns distribution. In general, the better the expected return, the less attractive are the variance, the skewness and the kurtosis. Similarly, if one wants to increase the skewness of his portfolio, this will come at the cost of higher variance and kurtosis. Hopefully, it seems however possible to reduce the variance, while keeping the kurtosis relatively low.

\section{The Financial Crisis and its Impact on Wine Prices}

In this section, we study the impact of the financial crisis on the wine market. In order to compensate for the absence of observations for the period 2007-2009 ${ }^{42}$, we employ the Liv-ex 100 and Liv-ex 500 indices in addition to our general and first growths indices. ${ }^{43}$ The Liv-Ex 500 assesses the price evolution of the 500 wines that are the most actively traded on London market place, while the Liv-Ex 100 only takes into account the 100 most often traded wines. As such, the Liv-Ex 500 is more representative of the dynamic of the complete wine market, while the Liv-Ex 100 focuses primarily on the most speculative wines.

Figure 4 shows the evolution of the various wine indices and the S\&P 500 between 1996 and 2007.44 All indices have been standardized in order to have base value 100 in July 2001. The S\&P 500 serves us as a benchmark of the evolution of US stock prices. Wine prices have skyrocketed during the period 2006-2008 and have then come back to more reasonable levels. The drop in the Liv-ex 100 in autumn 2008 is particularly spectacular and seems to be related to the financial crisis.

In order to complement graphical observations with a quantitative assessment, we calculate the correlations between the returns on the various wine and stock market indices. To avoid possible non-synchronous trading problems, we focus exclusively on quarterly returns. Furthermore, as wine returns are not normally distributed, we use the Spearman's rank correlation coefficient.

Table 8 shows the correlation between the various indices for three different periods: 1996-2001, 2001-2007 and 2007-2009. The correlation between the various wine indices has been consistently positive and significant (at the exception of the correlation between the general wine index and the Liv-ex 500, which is not significant at standard levels). Before 2001, our wine indices have been positively related with the S\&P 500, but interestingly the

\footnotetext{
42 Our sample period ends in February 2007.

${ }^{43}$ See www.liv-ex.com.

${ }^{44}$ Historical data for the Liv-ex 100 are only available since July 2001.
} 


\section{Figure 4}

\section{Evolution of the S\&P 500, Our General and First Growths Wine Indices} (until 2007) and the Liv-ex 100 and Liv-Ex 500 (since 2001)

Evolution of the indices over the period 1996-2009

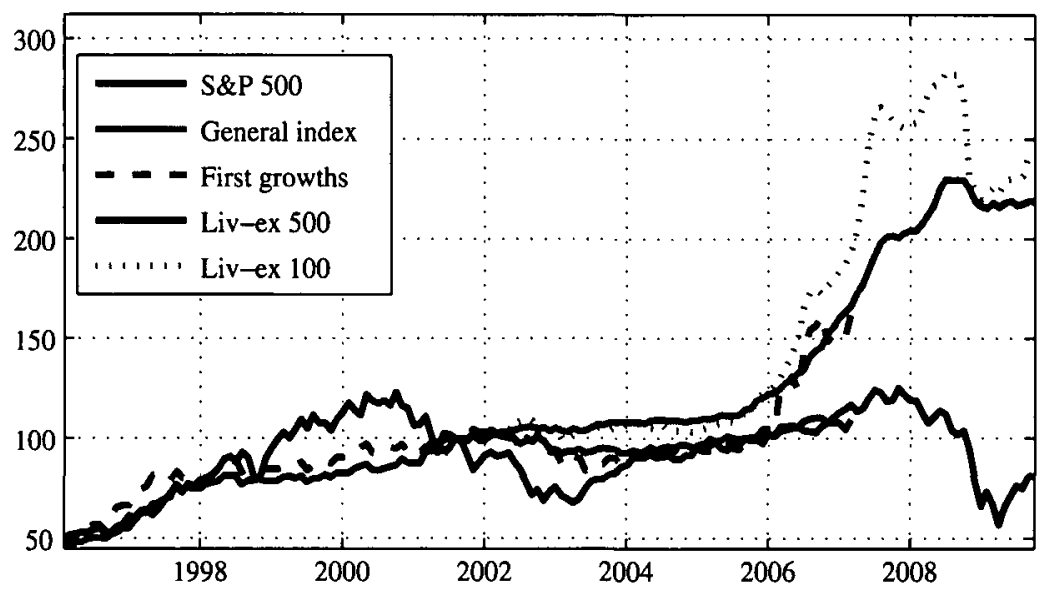

Table 8

Correlation Between Wine and Stock Market Indices from 1996 to 2009

\begin{tabular}{lcclllllc}
\hline & \multicolumn{2}{c}{$1996-2001$} & \multicolumn{9}{c}{$2001-2007$} & \multicolumn{2}{c}{ 2007-2009 } \\
\hline & GWI & FG & GWI & FG & L500 & L100 & L500 & L100 \\
S\&P 500 & $0.31^{* *}$ & $0.29^{* *}$ & -0.20 & $-0.22^{*}$ & 0.15 & 0.13 & $0.41^{* *}$ & $0.50^{* * *}$ \\
GWI & 1.00 & $0.94^{* * *}$ & 1.00 & $0.81^{* * *}$ & 0.14 & $0.23^{*}$ & - & - \\
FG & $0.94^{* * *}$ & 1.00 & $0.81^{* * *}$ & 1.00 & $0.30^{* *}$ & $0.24^{*}$ & - & - \\
L500 & - & - & 0.14 & $0.30^{* *}$ & 1.00 & $0.79^{* * *}$ & 1.00 & $0.80^{* * *}$ \\
L100 & - & - & $0.23^{*}$ & $0.14^{*}$ & $0.79^{* * *}$ & 1.00 & $0.80^{* * *}$ & 1.00 \\
\hline
\end{tabular}

GWI, FG, L500 and L100 are abbreviations for the general wine index, the first growths index, the Liv-ex 500 and Liv-ex $100 .{ }^{* * *}$, ** and * denote significativity at the $99 \%, 95 \%$ and $90 \%$ confidence level.

relationship has reverted during the period 2001-2007. On the other hand, the correlation between returns on Liv-ex indices and S\&P 500 has been positive (but not significant) during the same period. This suggests that Liv-ex indices are more closely related to the evolution of stock markets. This is presumably due to the fact that the Liv-ex indices trace the evolution of the most speculative wines, while our indices account for the evolution of many more wines, some of them much less speculative. From 2007 onwards, the Liv-ex indices and the S\&P 500 have demonstrated a strong correlation.

In order to gain more insight about the impact of the financial crisis on our results from the previous section (i.e. on the diversification benefits from investing in wine), we calculate time-varying correlation coefficients between the different wine and stock market 
indices. We calculate the correlations using rolling time windows of 24 months. We employ overlapping quarterly returns because of the small number of observations and also in order to smooth the dynamics of correlations. To account for the non-trivial returns distribution, we estimate $90 \%$-confidence bounds using the bootstrap approach. We resample 100,000 times the original data.

Figure 5 shows the evolution of correlations between (1) the general wine index and the S\&P 500 (until 2007) and (2) the Liv-ex 500 and the S\&P 500 (from 2001 onwards). One may notice that the correlation between wine prices and the S\&P 500 has followed a declining trend until 2005 when it reached a low. The correlation between the Liv-ex 500 and the S\&P 500 has been larger than the correlation between the general wine index and the S\&P 500. Again, we believe that this is because the Liv-ex 500 index gives more weight to speculative wines. Wine has played a defensive role during both the 1998 financial crisis and the burst of the dotcom bubble. On the other hand, wine prices have taken more time to rebound at the end of the 2001-2003 bear market. During the first part of the current crisis, i.e. before September 2008, the correlation has started to increase but, in August 2008, wine prices were still close to their all-time highs. At the same moment, the S\&P 500 was already $20 \%$ down from its 2007 peak.

\section{Figure 5}

Time-Varying Correlations Between the S\&P 500 Returns and the Returns on the Liv-ex 500 and Our General Wine Index

Time-varying correlations between wine and S\&P 500 returns

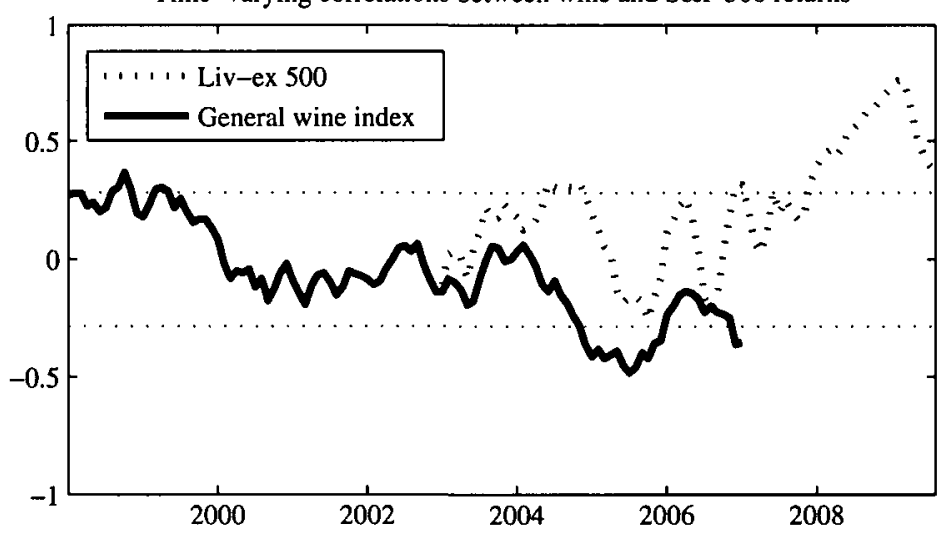

Note: Based on rolling time windows of 2 years to calculate the correlations.

When entering the eye of the financial tornado in October 2008, the correlation has increased tremendously (see Figure 5) and wine prices have fallen sharply. The most speculative wines (Liv-ex 100) have been the most violently hit. Between September and December, they have lost $25 \%$ versus $6 \%$ for the Liv-ex 500 . It is however worth to point out that the S\&P 500 has plunged by over $40 \%$ over these three months! This increasing correlation between asset classes can be explained by a well-known flight to liquidity 
phenomenon that has lead to a "correlation breakdown," which corresponds to a situation in which all asset classes move together thus making diversification strategies inoperative. The impact of such an event is usually limited in time and, therefore, it remains to see if the correlation will rapidly come back to its pre-crisis levels. This could well be the case as wine prices have stabilized since the end of 2008 (i.e. three months before the stock markets started to rebound). Figure 5 also suggests that the correlation has already started to decrease.

\section{Conclusion}

This paper studies the evolution of wine prices during the last decade (1996-2007) and analyzes their properties from an investor's viewpoint. Preliminary results show that investing in the wine market might permit to achieve an attractive performance in terms of both average returns and volatility. However, one has to note that this market is far from being homogeneous: the potential for price appreciation of a wine strongly depends on its vintage, its notoriety and ranking as well as its rating. Limited liquidity and market fragmentation make it difficult to establish a precise market price for any bottle of wine. Therefore someone wanting to invest in wines has to be armed with an excellent knowledge of the current conditions prevailing on the market.

We investigate if the wine market can be segmented in homogeneous subcategories. To this aim, we consider a set of wine indices defined on the basis of their ranking. The evidence suggests that these indices follow a unique trend; technically speaking, they are cointegrated. An interesting feature of these subsets of wines is that their short-term codependence is somewhat limited. Furthermore, the correlation of wines with equities is not very significant. This suggests that wines might be a useful diversification device. Indeed, an extensive portfolio allocation analysis shows that wines have to be overweighted relatively to equities in the optimal Sharpe-ratio portfolio. Including higher moments of the distribution does not alter this result: wines allow significantly increasing the skewness of an equity portfolio but equities are more appealing in terms of kurtosis. Even if we consider the costs associated with the holding and trading of wines, the latters still improve the riskreturn profile of an equity portfolio. According to a study of the evolution of wine prices during the last two years (in UK), we do not believe that the financial crisis and its impact on the wine market modify our conclusions. All asset classes have been hit sharply by Lehman's failure and, consequently, the correlation between wine and stock returns has increased very significantly. But the empirical evidence suggests that the correlation has already come back relatively close to its pre-crisis levels. Hence, at least from a diversification viewpoint, it looks still attractive to invest in wine.

In summary, the evidence provided in this paper demonstrates that wine might be an appealing alternative investment vehicle. Nevertheless, our opinion is that such an investment should follow some practical rules. First, one should only invest in wines if one has a real "epicurean" interest in wines. This is because such an investment requires having a 
very good knowledge of this complex market, which does not function the same way other financial markets do. Second, a long term perspective is necessary (as for equities); wines as other collectibles are also affected by business cycles. The recent financial crisis and its impact on the wine market provides a striking example: prices have dropped by up to $25 \%$ for the most speculative wines. Third, we advise against entering the wine market through investment funds. Such funds have large positions in highly illiquid assets. As such, if they had to get out of the market and to sell their positions quickly, they might incur large losses. Fourth, one has to focus on investment grade wines only and to diversify one's positions.

Wine economics remains an understudied realm of research, at least from a financial viewpoint. Now that data have become more easily available and are of better quality, we see several avenues for future research. First, it might be of interest to analyze whether this market is arbitrage-free or not; we suspect that this is not the case. For instance, one may employ a dynamic hedonic pricing model to identify under- and overevaluated wines and then design a trading strategy to take advantage of possible arbitrage opportunities. Second, the variables that lead the evolution of the wine market as a whole remain largely unknown. It might thus prove useful for forecasting purposes to get a better understanding of how such driving variables come into action. Third, it would also be interesting to extend the analysis to an international perspective, including important wine markets like England, France or Germany. Up to now, wine prices have always been investigated in a singlecountry framework; it is therefore unclear whether there is a unique international trend driving the market. And, of course, it would be definitely useful to study in details the impact of the financial crisis on the wine market. At the time being, it is still very difficult to figure out what would be the long-term impact of this event on wine prices.

\section{References}

Ashenfelter, O. (1989). How auctions work for wine and art. The Journal of Economic Perspectives, 3, 23-36.

Ashenfelter, O., Ashmore, D. and Lalonde, R. (1995). Bordeaux wine vintage quality and the weather. Chance, 8, 7-14.

Ashenfelter, O. (2010). Predicting the quality and prices of Bordeaux wine. Journal of Wine Economics, $5(1), 40-52$.

Baek, E.G. and Brock, W.A. (1992). A general test for nonlinear Granger causality: bivariate model. Working Paper, Iowa State University and University of Wisconsin, Madison.

Benfratello, L. and Piacenza, M. and Sacchetto, S. (2009). What drives market prices in the wine Industry? Estimation of a hedonic model for Italian premium wines. Applied Economics, 41(17), 2197-2209.

Burton, B.J. and Jacobsen, J.P. (1999). Measuring Returns on investments in collectibles. Journal of Economic Perspectives, 13(4), 193-212.

Burton, B.J. and Jacobsen, J.P. (2001). The rate or return on investment in wine. Economic Inquiry, 39, 337-350.

Cardebat, J.M. and Figuet, J.M. (2004). What explains Bordeaux wine prices? Applied Economics Letters, 11, 293-296. 
Christensen, B.J. and Meunier, V. (2006). Forward and spot prices: testing the expectations hypothesis in the Bordeaux "en primeur" wine market. Working Paper, University of Aarhus.

Combris, P. and Lecocq, S. and Visser, M. (1997). Estimation of a hedonic price equation for Bordeaux wine: does quality matter? The Economic Journal, 107, 390-402.

Combris, P. and Lecocq, S. and Visser, M. (2000). Estimation of a hedonic price equation for Burgundy wine. Applied Economics, 32, 961-967.

Davies, R.J. and Kat, H.M. and Lu, S. (2009). Fund of hedge funds portfolio selection: a multipleobjective approach. Journal of Derivatives and Hedge Funds, 15(2), 91-115.

Di Vittorio, A. and Ginsburgh, V. (1996). Pricing red wines of Medoc vintages from 1949 to 1989 at Christies auctions. Journal de la Société Statistique de Paris, 137, $19-49$.

Diks, C. and Panchenko, V. (2006). A new statistic and practical guidelines for nonparametric Granger causality testing. Journal of Economic Dynamics and Control, 30, 1647-1669.

Engle, R. (2002). Dynamic conditional correlation: a simple class of multivariate generalized autoregressive conditional heteroskedasticity models. Journal of Business and Economic Statistics, 20(3), 339-350.

Fogarty, J.J. (2006a). Wine investment, pricing and substitutes. Thesis, University of Western Australia. School of Economics and Commerce.

Fogarty, J.J. (2006b). The return to Australian fine wine. European Review of Agricultural Economics, 33, 542-561.

Fogarty, J.J. (2007). Rethinking wine investment in the UK and Australia. American Association of Wine Economists, Working Paper No. 6.

Hamilton, J.D. (1994). Time Series Analysis. Princeton: Princeton University Press.

Hiemstra, C. and Jones, J.D. (1994). Testing for linear and nonlinear Granger causality in the stock price-volume relation. Journal of Finance, 49(5), 1639-1664.

Jaeger, E. (1981). To save or savor: the rate of return to storing wine. The Journal of Political Economy, 89, 584-592.

Jondeau, E. and Poon, S.-H. and Rockinger, M. (2007). Financial Modeling Under Non-Gaussian Distributions. London: Springer Finance.

Jondeau, E. and Rockinger, M. (2006). Optimal portfolio alocation under higher moments. European Financial Management, 12(1), 29-55.

Jones, G.V. and Storchmann, K.H. (2001). Wine market prices and investment under uncertainty: an econometric model for Bordeaux Crus Classés. Agricultural Economics, 26, 115-133.

Krasker, W.S. (1979). The rate of return to storing wines. The Journal of Political Economy, 87(6), 1363-1367.

Lay, K.K. and Yu, L. and Wang, S. (2006). Mean-variance-skewness-kurtosis-based portfolio optimization. Proceedings of the First International Multi-Symposiums on Computer and Computational Sciences, 2, 292-297.

Lecocq, S. and Visser, M. (2006). What determines wine prices: objective vs. sensory characteristics. Journal of Wine Economics, 1, 42-56.

Mahenc, P. and Meunier (2006). Early sales of Bordeaux grands crus. Journal of Wine Economics, 1(1), 57-74.

Markowitz, H.M. (1952). Portfolio selection. Journal of Finance, 7, 77-91.

Oczkowski, E. (2001). Hedonic wine price functions and measurement error. The Economic Record, 77, 374-382.

Sanning, L.W. and Shaffer, S. and Sharratt, J.M. (2008). Bordeaux wine as a financial investment. Journal of Wine Economics, 3, 51-71.

Tsay, R.S. (2002). Analysis of Financial Time Series. Hoboken, New Jersey: John Wiley and Sons. 


\section{Appendix: List of Estates}

First Growths (according to our ranking): Lafite Rothschild (official classification: 1st Growth, Pauillac), Latour (1st Growth, Pauillac), Mouton Rothschild (1st Growth, Pauillac), Château Margaux (1st Growth, Margaux), Haut Brion (1st Growth, Pessac-Léognan), La Mission Haut Brion (Cru Classé, Pessac-Léognan), Lafleur (Pomerol), Pétrus (Pomerol), Le Pin (Pomerol), Ausone (1st Growth "A", Saint-Emilion), Cheval Blanc (1st Growth "A", Saint-Emilion).

Second Growths: Cos d'Estournel (2nd Growth, Saint-Estèphe), Montrose (2nd Growth, Saint-Estèphe), Lynch Bages (5th Growth, Pauillac), Pichon Longueville Baron (2nd Growth, Pauillac), Pichon Longueville Comtesse (2nd Growth, Pauillac), Ducru Beaucaillou (2nd Growth, Saint-Julien), Léoville Las Cases (2nd Growth, Saint-Julien), Palmer (3rd Growth, Margaux), L'Evangile (Pomerol), Trotanoy (Pomerol), Angélus (1st Growth “B”, Saint-Emilion), Pavie (1st Growth "B”, Saint-Emilion).

Third Growths: Calon Ségur (3rd Growth, Saint-Estèphe), Grand Puy Lacoste (5th Growth, Pauillac), Gruaud Larose (2nd Growth, Saint-Julien), Léoville Barton (2nd Growth, Saint-Julien), Léoville Poyferré (2nd Growth, Saint-Julien), Talbot (4th Growth, Saint-Julien), Certan de May (Pomerol), Clinet (Pomerol), La Conseillante (Pomerol), L'Eglise Clinet (Pomerol), Vieux Château Certan (Pomerol), Tertre Roteboeuf (SaintEmilion), Troplong Mondot (1st Growth "B”, Saint-Emilion).

Fourth Growths: Pontet Canet (5th Growth, Pauillac), Beychevelle (4th Growth, SaintJulien), Rauzan Ségla (2nd Growth, Margaux), Sociando Mallet (Haut-Médoc), Pape Clément (Cru Classé, Pessac-Léognan), Bon Pasteur (Pomerol), Fleur de Gay (Pomerol), La Fleur Pétrus (Pomerol), Latour à Pomerol (Pomerol), Figeac (1st Growth "B", SaintEmilion), Monbousquet (Grand Cru Classé, Saint-Emilion), Pavie Decesse (Grand Cru Classé, Saint-Emilion), Pavie Macquin (1st Growth “B”, Saint-Emilion).

Fifth Growths: Lafon Rochet (4th Growth, Saint-Estèphe), Meyney (Cru Bourgeois supérieur, Saint-Estèphe), Les Ormes de Pez (Cru Bourgeois exceptionnel, Saint-Estèphe), Armailhac (5th Growth, Pauillac), Clerc Milon (5th Growth, Pauillac), Branaire Ducru (4th Growth, Saint-Julien), Gloria (Saint-Julien), Smith Haut Lafitte (Cru Classé, PessacLéognan), Clos l'Eglise (Pomerol), Nénin (Pomerol), L'Arrosée (Grand Cru Classé, SaintEmilion), Beau Séjour Bécot (1st Growth "B", Saint-Emilion), Beau Séjour Duffau (1st Growth "B", Saint-Emilion), Canon (1st Growth "B", Saint-Emilion), Lagrange (3rd Growth, Saint-Julien), Brane Cantenac (2nd Growth, Margaux), Giscours (3rd Growth, Margaux), Lascombes (2nd Growth, Margaux), Cantmerle (5th Growth, Médoc), La Lagune (3rd Growth, Médoc), de Chevalier (Cru Classé, Pessac-Léognan), Canon Gaffelière (Grand Cru Classé, Saint-Emilion), Clos de l'Oratoire (Grand Cru Classé, Saint-Emilion), La Dominique (Grand Cru Classé, Saint-Emilion), La Gaffelière (1st Growth "B", SaintEmilion), Magdelaine (1st Growth "B", Saint-Emilion), Quinault l'Enclos (SaintEmilion). 
Garage Wines: Bellevue Mondotte (Saint-Emilion), Clos de Sarpe (Saint-Emilion), La Gomerie (Saint-Emilion), Gracia (Saint-Emilion), Hermitage (Saint-Emilion), Lynsolence (Saint-Emilion), Magrez Fombrauge (Saint-Emilion), La Mondotte (Saint-Emilion), Rol Valentin (Saint-Emilion), Valandraud (Saint-Emilion).

Second Wines: Carruades de Lafite (Second wine of Lafite Rothschild, Pauillac), Forts de Latour (Second wine of Latour, Pauillac), Clos du Marquis (Second wine of Léoville Las Cases, Saint-Julien), Pavillon Rouge de Ch. Margaux (Second wine of Château Margaux, Margaux), Bahans de Haut Brion (Second wine of Haut-Brion, Pessac-Léognan), Pensées de Lafleur (Second wine of Lafleur, Pomerol). 